\title{
Performance and grain yield stability of maize populations developed using marker-assisted recurrent selection and pedigree selection procedures
}

\author{
Yoseph Beyene $\cdot$ Kassa Semagn $\cdot$ Stephen Mugo $\cdot$ Boddupalli M. Prasanna \\ Amsal Tarekegne $\cdot$ John Gakunga $\cdot$ Pierre Sehabiague $\cdot$ Barbara Meisel \\ Sylvester O. Oikeh $\cdot$ Michael Olsen $\cdot$ Jose Crossa
}

Received: 12 July 2015/Accepted: 2 November 2015/Published online: 9 November 2015

(C) The Author(s) 2015. This article is published with open access at Springerlink.com

\begin{abstract}
A marker-assisted recurrent selection (MARS) program was undertaken in sub-Saharan Africa to improve grain yield under drought-stress in 10 biparental tropical maize populations. The objectives of the present study were to evaluate the performance of $\mathrm{C}_{1} \mathrm{~S}_{2}$-derived hybrids obtained after three MARS cycles (one cycle of recombination $\left(\mathrm{C}_{1}\right)$, followed by two generations of selfing $\left(\mathrm{S}_{2}\right)$, and to study yield stability under both drought-stress (DS) and well-watered (WW) conditions. For each of the 10 populations, we evaluated hybrids developed by crossing 47-74 $\mathrm{C}_{1} \mathrm{~S}_{2}$ lines advanced through MARS, the best five $\mathrm{S}_{5}$ lines developed through pedigree selection, and the founder parents with a single-cross tester from a complementary heterotic group. The
\end{abstract}

Electronic supplementary material The online version of this article (doi:10.1007/s10681-015-1590-1) contains supplementary material, which is available to authorized users.

Y. Beyene $(\bowtie) \cdot$ K. Semagn · S. Mugo ·

B. M. Prasanna $\cdot$ J. Gakunga $\cdot$ M. Olsen

International Maize and Wheat Improvement Center

(CIMMYT), P.O. Box 1041, Village Market,

Nairobi 00621, Kenya

e-mail: Y.Beyene@cgiar.org

A. Tarekegne

CIMMYT, $12.5 \mathrm{~km}$ peg Mazowe Road, Mount Pleasant,

P.O. Box MP163, Harare, Zimbabwe

P. Sehabiague

Monsanto SAS, Croix de Pardies, BP21,

40305 Peyrehorade, France hybrids and five commercial checks were evaluated in Kenya under 1-3 DS and 3-5 WW conditions with two replications. Combined across DS locations, the top $10 \mathrm{C}_{1} \mathrm{~S}_{2}$-derived hybrids from each of the 10 biparental populations produced $0.5-46.3$ and 11.1-55.1\% higher mean grain yields than hybrids developed using pedigree selection and the commercial checks, respectively. Across WW locations, the best 10 hybrids derived from $\mathrm{C}_{1} \mathrm{~S}_{2}$ of each population produced 3.4-13.3 and 7.9-36.5\% higher grain yields than hybrids derived using conventional pedigree breeding and the commercial checks, respectively. Mean days to anthesis of the best $10 \mathrm{C}_{1} \mathrm{~S}_{2}$ hybrids were comparable to those of hybrids developed using the pedigree method, the founder parents and the commercial checks, with a maximum difference of 3.5 days among the different groups. However, plant height was significantly $(\mathrm{P}<0.01)$ different in most pairwise comparisons. Our results showed the

B. Meisel

Monsanto South Africa (Pty) Ltd,

P.O. Box 69933, Bryanston 2021, South Africa

S. O. Oikeh

African Agricultural Technology Foundation (AATF),

P.O. Box 30709-00100, Nairobi, Kenya

J. Crossa

International Maize and Wheat Improvement Center (CIMMYT), Apdo. Postal 6-641, 06600 Mexico, DF, Mexico 
superiority of MARS over pedigree selection for improving diverse tropical maize populations as sources of improved lines for stress-prone environments and thus MARS can be effectively integrated into mainstream maize breeding programs.

Keywords Africa · Drought - Molecular breeding · SNP $\cdot$ Rapid cycle recombination $\cdot$ Testcross evaluation

\section{Introduction}

Maize, a staple food in many sub-Saharan African countries, is grown by millions of resource-poor smallholder farmers. Between 2009 and 2011, maize was grown on more than 25 million hectares in subSaharan Africa (SSA) (Shiferaw et al. 2011), accounting for $7.5 \%$ of global production. Average maize yield in SSA is $1.8 \mathrm{Mg} \mathrm{ha}^{-1}$, which is significantly lower than the yield in other maize-growing regions in the developing world. Recurrent drought is one of the major abiotic stresses in SSA, with approximately $22 \%$ of mid-altitude/subtropical and $25 \%$ of lowland tropical maize growing regions affected annually (Heisey and Edmeades 1999). Drought is expected to increase in severity due to the changing climate. Therefore, development and deployment of tropical maize germplasm with relevant agronomic and adaptive traits is key to enhance the food security and livelihoods of maize farming communities.

The ability to quickly develop germplasm with resistance to important abiotic and biotic stresses will be critical to the resilience of cropping systems in the face of climate change. Conventional breeding methods have a proven track record of improving tolerance for abiotic stresses (DTMA 2015). However, progress in breeding for drought tolerance using conventional approaches can be slow due to the polygenic nature of most stress-related traits, requiring accumulation of several quantitative trait loci (QTL) into adapted genetic backgrounds. In order to uncover and characterize genomic regions or QTLs associated with drought stress, several researchers (Veldboom and Lee 1996; Ribaut et al. 1997; Tuberosa et al. 2002; Almeida et al. 2013; Semagn et al. 2013) have reported a number of QTL for grain yield and other traits under both drought stress and well-watered conditions. In most cases, however, individual QTLs for highly polygenic traits explain only a small proportion of the phenotypic variance, and are highly dependent on genetic background and environmental conditions (Semagn et al. 2013).

Molecular marker-assisted breeding, including marker-assisted backcrossing (MABC), marker-assisted recurrent selection (MARS) and genomic selection (GS), in combination with high-throughput and precise phenotyping, doubled haploidy and yearround nurseries, can significantly accelerate the development of climate resilient maize germplasm (Prasanna et al. 2013; Xu et al. 2012). MARS is a breeding approach that aims to accumulate favorable alleles for a relatively large number of QTL in a given population using a subset of markers that are significantly associated with target traits (Bernardo 2008). GS incorporates all available marker information into a model to simultaneously predict genetic values of breeding progenies for selection, enabling accumulation of favorable alleles for major and minor QTL through multiple generations of recombination (Meuwissen et al. 2001). Recently, Beyene et al. (2015a) and Semagn et al. (2015) reported genetic gains achieved through GS and MARS in 8 and 10 tropical biparental maize populations, respectively. These studies involved genotyping $148-300 \mathrm{~F}_{2: 3}\left(\mathrm{C}_{0}\right)$ progenies with 190-286 markers, evaluating testcrosses under WW and DS conditions and advancing selected lines using GS and MARS. In both studies, each population was represented by seed bulks containing equal amounts of seed of $\mathrm{C}_{0}, \mathrm{C}_{1}, \mathrm{C}_{2}, \mathrm{C}_{3}$, parents, $\mathrm{F}_{1} \mathrm{~s}$, and lines developed via pedigree selection. Five commercial checks were included for comparison. Beyene et al. (2015a) compared GS with pedigree selection across eight biparental tropical maize populations, and reported that the average gain per cycle from GS across eight populations was $0.086 \mathrm{t} \mathrm{ha}^{-1}$. Average grain yield of $\mathrm{C}_{3}$-derived hybrids was significantly higher than that of hybrids derived from $\mathrm{C}_{0}$. Hybrids derived from $\mathrm{C}_{3}$ produced $7.3 \%$ higher grain yield than those developed through conventional pedigree breeding.

Semagn et al. (2015) reported that the average gain per cycle using MARS across 10 populations was $0.1837 \mathrm{t} \mathrm{ha}^{-1}$ under WW and $0.045 \mathrm{t} \mathrm{ha}^{-1}$ under DS conditions. Combined across DS environments, $\mathrm{C}_{3^{-}}$ derived hybrids produced 6.0, 8.3 and $37.8 \%$ higher grain yields than hybrids derived from conventional 
pedigree breeding, parental lines and commercial checks, respectively. Across WW trials, the average grain yield of $\mathrm{C}_{3}$ hybrids was significantly $(\mathrm{P}<0.05)$ higher than those hybrids derived $\mathrm{C}_{0}$, the pedigree method and the commercial checks. In both studies, the authors used a composite bulk to represent lines extracted from each selection cycle instead of using individual lines. In this study, we report the testcross performance of hybrids developed from 47 to 74 individual $\mathrm{C}_{1} \mathrm{~S}_{2}$ lines instead of bulks derived from 10 MARS populations and evaluated under both managed drought-stress and optimum conditions. The objectives of the present study were: (1) to compare the overall gain in grain yield of all $\mathrm{C}_{1} \mathrm{~S}_{2}$-derived hybrids with that of hybrids developed through conventional pedigree breeding method and (2) to compare yield stability of hybrids from a subset of selected populations developed through MARS and pedigree selection.

\section{Materials and methods}

\section{Genetic materials}

Three cycles of MARS were completed on 10 tropical biparental populations. Detailed descriptions of the methodology and the results are given elsewhere (Beyene et al. 2015b) and briefly summarized here. Testcrosses were generated by crossing the $F_{2: 3}$ families $\left(\mathrm{C}_{0}\right)$ from each population with a single-cross tester from a complementary heterotic group and evaluated under 2-3 managed drought stresses and 3-4 well-watered conditions in Kenya, Zimbabwe and Zambia. Each $\mathrm{C}_{0}$ population was genotyped with 190-225 SNPs and QTL analysis was performed for each population. Three selection cycles were conducted using a subset of 55-87 SNPs that were significantly associated with grain yield and anthesissilking interval. Selected $\mathrm{C}_{0}$ families were first intermated to form Cycle $1\left(C_{1}\right)$, followed by selfing of superior $\mathrm{C}_{1}$ plants for two generations to form $\mathrm{C}_{1} \mathrm{~S}_{1}$ and $\mathrm{C}_{1} \mathrm{~S}_{2}$. At each recurrent selection cycle, selected individuals were genotyped with the significantly associated markers to increase favorable allele frequency. In each population, the top eight families from $\mathrm{C}_{0}$ were also advanced using a pedigree selection scheme. The various steps followed during MARS and pedigree phenotypic selection were illustrated by Beyene et al. (2015b).

Formation of testcrosses and phenotypic evaluation

From each population, 47-74 $\mathrm{C}_{1} \mathrm{~S}_{2}$ lines developed through MARS, five $\mathrm{S}_{5}$ lines developed via phenotypic pedigree selection, and the two founder parents (P1 and P2) were crossed to a single-cross tester (CML395/CML444) at the Maize Research Station of Kenya Agriculture and Livestock Research Organization (KALRO), Kiboko, Kenya. This tester has proven to be useful in hybrid formation for subtropical and mid-altitude environments, and is also used as a parent in many commercial three-way-cross hybrids in SSA (Beyene et al. 2011, 2013). Experimental lines were used as female parents, and the single-cross tester was used as the male parent. Seeds were harvested and bulked within each female row plot for use in the testcross evaluation. Testcrosses of each population, together with five commercial checks (CZH0616, H513, WH505, DK8053, and Pioneer 3253), were evaluated in 3-5 WW and 1-3 DS locations in Kenya in 2013 and 2014. An alpha-lattice design with two replications per location was utilized for the trials. The DS trials were conducted during the dry (rain-free) season by withdrawing irrigation starting 2 weeks before flowering through harvest, whereas the WW trials were conducted during the rainy season, with supplemental irrigation applied as needed. Entries were planted in two-row plots, $5 \mathrm{~m}$ long, with $0.75 \mathrm{~m}$ spacing between rows and $0.25 \mathrm{~m}$ between hills. Two seeds per hill were initially planted and then thinned to one plant per hill at 3 weeks after emergence to obtain a final plant population density of 53,333 plants per hectare. Fertilizers were applied at the rate of $60 \mathrm{~kg} \mathrm{~N}$ and $60 \mathrm{~kg} \mathrm{P}_{2} \mathrm{O}_{5}$ per ha as recommended for the area. Nitrogen was applied twice: at planting and 6 weeks after emergence. Fields were kept free of weeds by hand weeding.

Data collection

Data on grain yield (GY), plant height $(\mathrm{PH})$ and anthesis date (AD) were collected. $\mathrm{AD}$ was recorded as the number of days from planting to when $50 \%$ of the plants had shed pollen. PH was measured as the 
distance from the base of the plant to the height of the first tassel branch. In DS trials, ears were harvested from each plot and all were shelled and weighed to determine the grain yield and percent grain moisture. In the WW experiments, ears harvested from each plot were weighed, sub-samples were shelled and grain moisture was determined on the sub-samples of grain. Grain yield was estimated assuming a shelling percentage of $80 \%$ and adjusted to $125 \mathrm{~g} / \mathrm{kg}$ moisture content.

\section{Statistical analysis}

Analysis of variance for grain yield, anthesis date and plant height within and across DS and WW locations was performed using the PROC MIXED procedure of SAS (SAS Institute 2009) considering locations and incomplete blocks as random effects and entries as fixed effects. For each population, the analyses were performed on all entries and also on groups of entries corresponding to test-crosses involving: (i) $\mathrm{C}_{1} \mathrm{~S}_{2}$ lines; (ii) $\mathrm{S}_{5}$ lines extracted through phenotypic pedigree selection; (iii) commercial checks; and (iv) founder parents used for making the original populations. Contrasts were made to compare the performance of all $\mathrm{C}_{1} \mathrm{~S}_{2}$ and the best $10 \mathrm{C}_{1} \mathrm{~S}_{2}$ hybrids versus five hybrids from the conventional pedigree scheme, founder parents and five commercial check hybrids. Stability analysis was done using the linear-bilinear site regression models (SREG) (Crossa and Cornelius 1997).

\section{Results}

The combined analysis of variance across WW and DS environments showed highly significant differences among genotypes for grain yield, plant height and anthesis date. The interactions between genotypes and environments (GE) were also significant (data not shown). For most populations, the proportion of genotype to GE variance was higher for WW than DS, indicating that GE interaction was severe under drought stress than optimum-moisture conditions (Supplementary material S1). Genotypic variance for grain yield was 23-100\% larger under WW than under DS conditions. For anthesis date, variance of genotypes was 3-74\% larger under WW than under DS conditions for eight populations, but it was
39-82 \% larger under DS than under WW conditions for two other populations (Supplementary material S1). Heritability estimates for grain yield were slightly higher under WW (0.3-0.8) than under DS (0-0.5) conditions. Heritability estimates for anthesis date and plant height were considerably higher under WW than under DS conditions (Table 1).

Grain yield under drought stress conditions

Mean grain yields of all $\mathrm{C}_{1} \mathrm{~S}_{2}$-derived hybrids across DS environments ranged from 2.14 to $3.01 \mathrm{t} \mathrm{ha}^{-1}$ (Table 1; Fig. 1), and the overall average was $2.61 \mathrm{t} \mathrm{ha}^{-1}$. Mean grain yield of hybrids developed from all $\mathrm{C}_{1} \mathrm{~S}_{2}$ lines within each population was $1.7-10.8 \%$ higher than that of hybrids derived from pedigree methods in five populations (1008, 1017, 1019, 1023 and 1028), and 3.4-12.4\% lower in the remaining five populations, but nearly all pairwise comparisons were not statistically significant (Supplementary material S2). However, each population was represented by $47-74 \mathrm{C}_{1} \mathrm{~S}_{2}$-derived hybrids, which is considerably higher than hybrids derived from five $\mathrm{S}_{5}$ lines using the pedigree method, five commercial checks and the founder parents. To make a reasonable comparison of the gains made through MARS, the best $10 \mathrm{C}_{1} \mathrm{~S}_{2}$ derived hybrids were compared with hybrids derived using the pedigree scheme, commercial checks and founder parents. Across DS experiments, mean grain yields of the best $10 \mathrm{C}_{1} \mathrm{~S}_{2}$-derived hybrids in all populations except population 1016 were significantly $(P \leq 0.01)$ higher than mean grain yields of hybrids formed from pedigree-derived lines, commercial checks, and the founder parents (Fig. 1, Supplementary material S2). Excluding population 1016, the mean grain yield of the best $10 \mathrm{C}_{1} \mathrm{~S}_{2}$-derived hybrids were $14.2-46.3 \%\left(0.359-0.888 \mathrm{t} \mathrm{ha}^{-1}\right), 10.3-55.1 \%$ $\left(0.310-1.247 \mathrm{t} \mathrm{ha}^{-1}\right)$, and 4.0-53.0\% (0.098-1.152 t $\mathrm{ha}^{-1}$ ) higher than those of pedigree-derived hybrids, the commercial checks and the founder parents, respectively (Fig. 1, Supplementary material S2). In population 1016, the mean of the best $10 \mathrm{C}_{1} \mathrm{~S}_{2}$-derived hybrids produced significantly $(P \leq 0.05)$ higher grain yield $(10.3 \%)$ than the mean of the commercial checks. Combined across DS environments and all populations, the best 10 hybrids involving $\mathrm{C}_{1} \mathrm{~S}_{2^{-}}$ derived lines produced $22.6 \% \quad\left(562 \mathrm{~kg} \mathrm{ha}^{-1}\right)$, $33.8 \% \quad\left(750 \mathrm{~kg} \mathrm{ha}^{-1}\right)$ and $27.8 \% \quad\left(916 \mathrm{~kg} \mathrm{ha}^{-1}\right)$ higher grain yield than hybrids formed from 


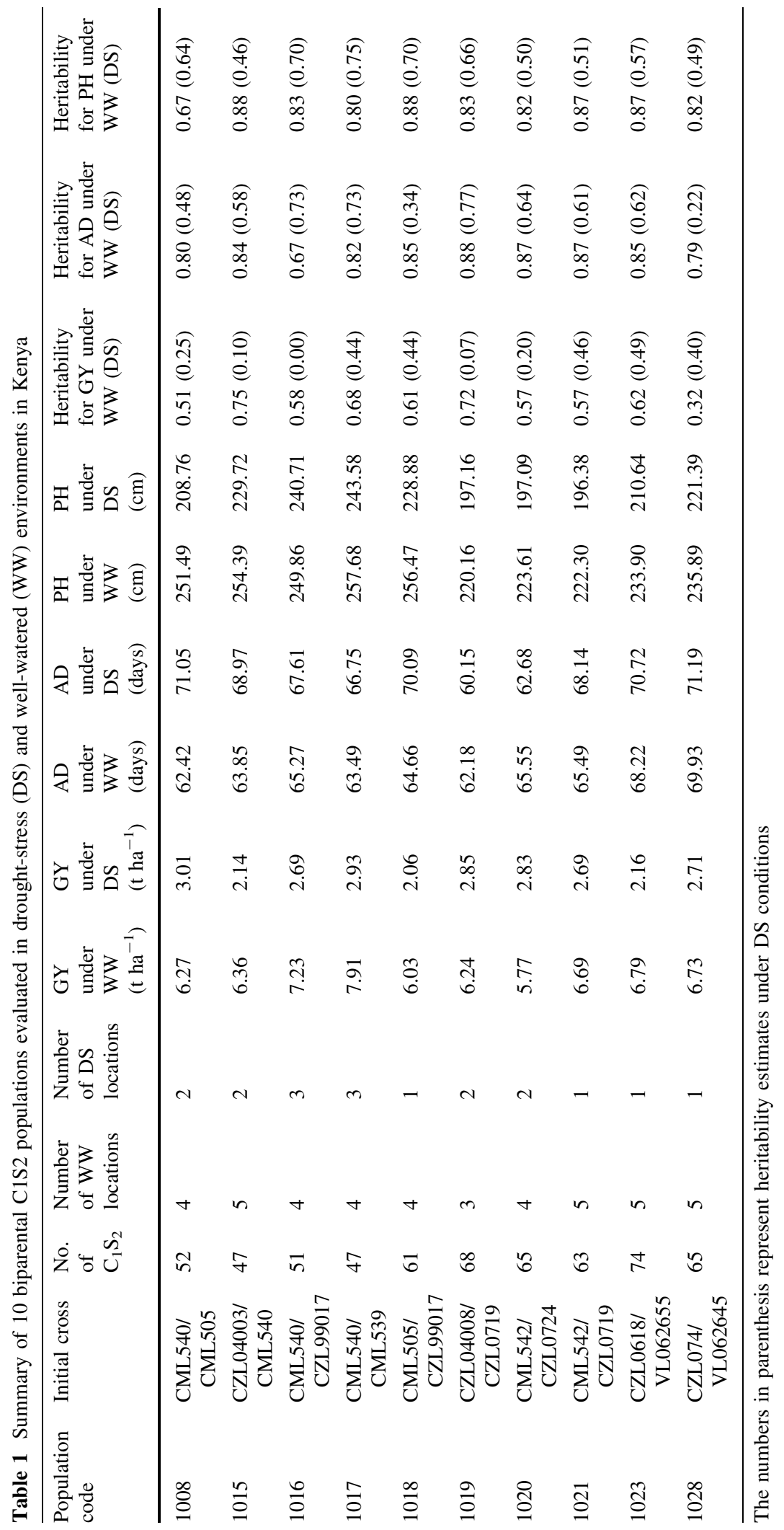


Fig. 1 Comparison of mean grain yield of testcross of all $\mathrm{C}_{1} \mathrm{~S}_{2}$ lines, the best 10 $\mathrm{C}_{1} \mathrm{~S}_{2}$ lines, five lines from conventional pedigree selection, founder parents and five commercial checks evaluated in managed drought-stress and wellwatered conditions in Kenya
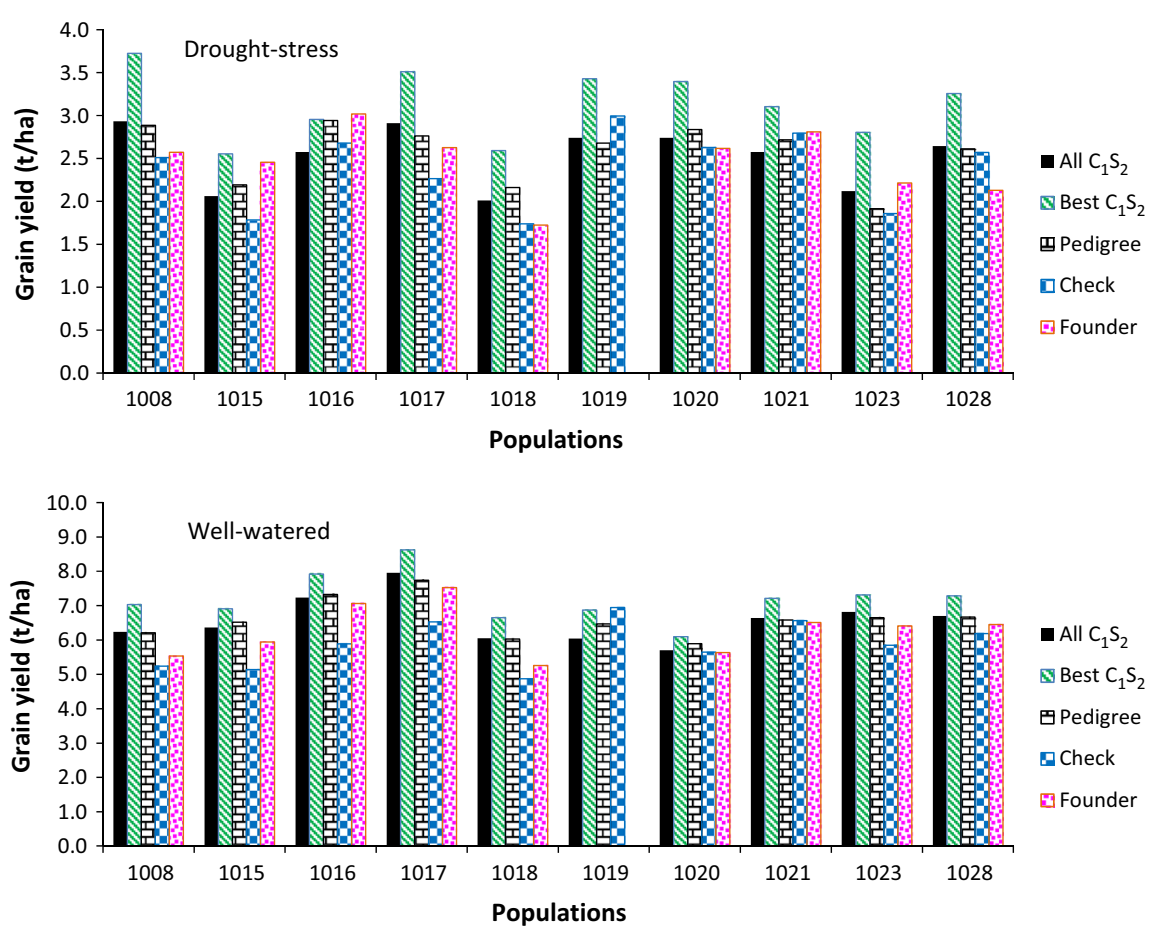

pedigree-derived lines, commercial checks and founder parents, respectively (Supplementary material S2).

Although grain yield was the primary target trait, anthesis date and plant height were also analyzed to determine if grain yield gain was related to a significant change in either trait. The best 10 hybrids involving $\mathrm{C}_{1} \mathrm{~S}_{2}$-derived lines showed a difference of 0-1.5 days to flowering with those hybrids formed from pedigree-derived lines and up to 3.5 days difference compared with both the commercial checks and the founder parents (Fig. 2, Supplementary material S2). For PH, the mean of the best 10 $\mathrm{C}_{1} \mathrm{~S}_{2}$-derived hybrids from three populations (populations 1017, 1019, and 1023) was significantly taller than the mean of the five hybrids formed from lines derived using the pedigree method (Fig. 3, Supplementary material S2). Additionally, the mean plant heights of the best 10 hybrids involving $\mathrm{C}_{1} \mathrm{~S}_{2^{-}}$ derived lines in nine of the ten populations were significantly higher than that of the commercial checks (Fig. 3).

Grain yield under well-watered conditions

As shown in Table 1 and Fig. 1, mean grain yield of testcrosses evaluated in WW environments varied from $5.77 \mathrm{t} \mathrm{ha}^{-1}$ (population 1020) to $7.91 \mathrm{t} \mathrm{ha}^{-1}$ (population 1017), with an overall average of $6.60 \mathrm{tha}^{-1}$. Mean grain yields of hybrids developed from all $\mathrm{C}_{1} \mathrm{~S}_{2}$ lines within each population showed a 0.4-2.8\% advantage over those hybrids involving pedigree-derived lines in six populations $(1008,1017$, 1018, 1021, 1023 and 1028), but showed a 1.3-6.6\% reduction compared to those of the other four populations (Fig. 1, Supplementary material S2). All contrasts between the mean grain yield of the best 10 hybrids formed from $\mathrm{C}_{1} \mathrm{~S}_{2}$-derived lines versus the mean grain yield of the five hybrids involving pedigree derived lines, the commercial checks and the founder parents were significant $(P \leq 0.01)$ (Supplementary material S2). The best 10 hybrids of $\mathrm{C}_{1} \mathrm{~S}_{2}$-derived lines per population produced (a) 3.4-13.3\% higher grain yield than those developed using lines through the pedigree method, (b) 9.9-36.5\% higher grain yield than the commercial checks (except population 1019, which showed a $1.1 \%$ reduction), and (c) 8.1-27.0\% higher grain yield than the founder parents. Taking into account the time invested in developing the lines and using the grain yield of the founder parents as a baseline, the top $10 \mathrm{C}_{1} \mathrm{~S}_{2}$-derived hybrids on average produced $214.8 \mathrm{~kg} \mathrm{ha}^{-1}$ year $^{-1}$ under WW conditions, which is approximately double 
Fig. 2 Comparison of mean anthesis date of testcrosses from all $\mathrm{C}_{1} \mathrm{~S}_{2}$ lines, the best $10 \mathrm{C}_{1} \mathrm{~S}_{2}$ lines, five lines from conventional pedigree selection, founder parents and five commercial checks evaluated under managed drought-stress and well-watered conditions in Kenya
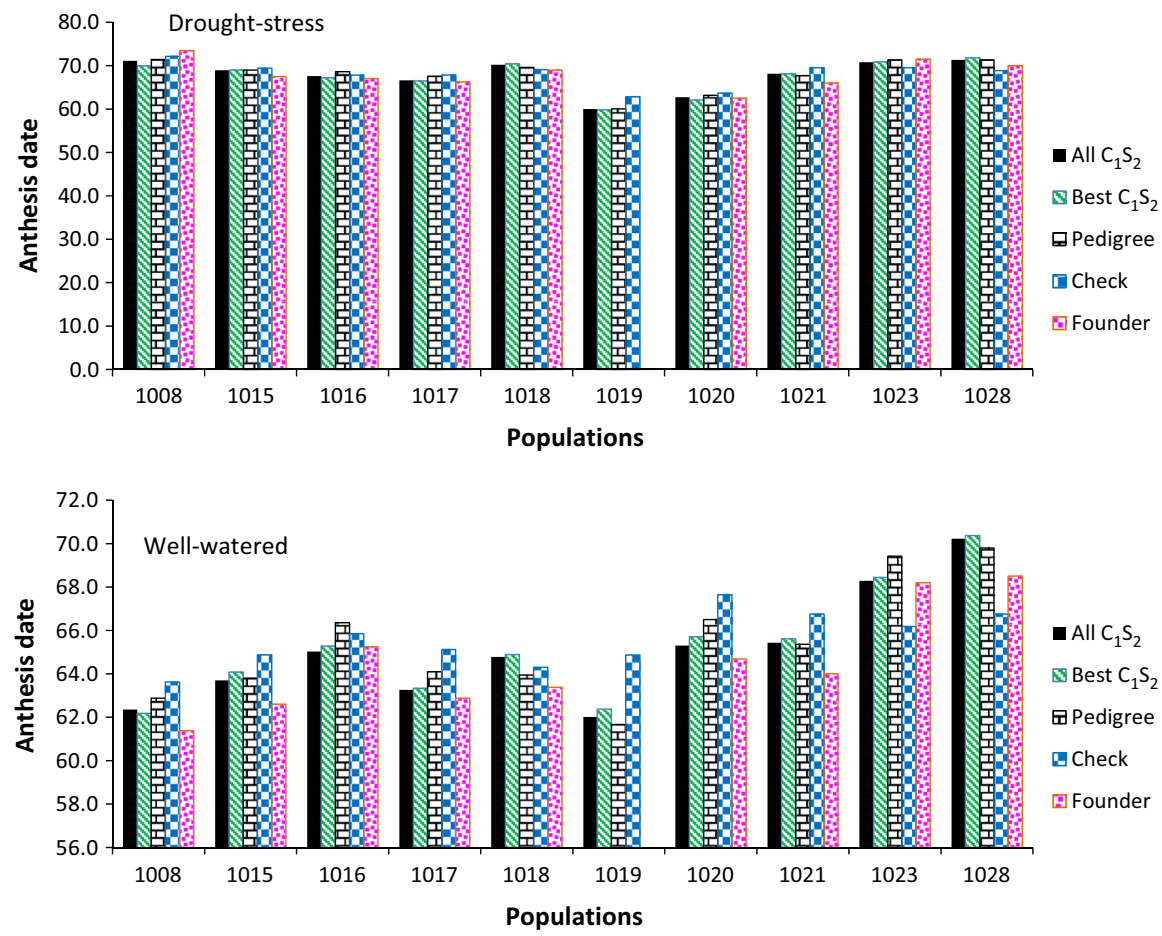

Fig. 3 Comparison of mean plant height of testcrosses from all $\mathrm{C}_{1} \mathrm{~S}_{2}$ lines, the best $10 \mathrm{C}_{1} \mathrm{~S}_{2}$ lines, five lines from conventional pedigree selection, founder parents and five commercial checks evaluated in managed drought-stress and well-watered conditions in Kenya
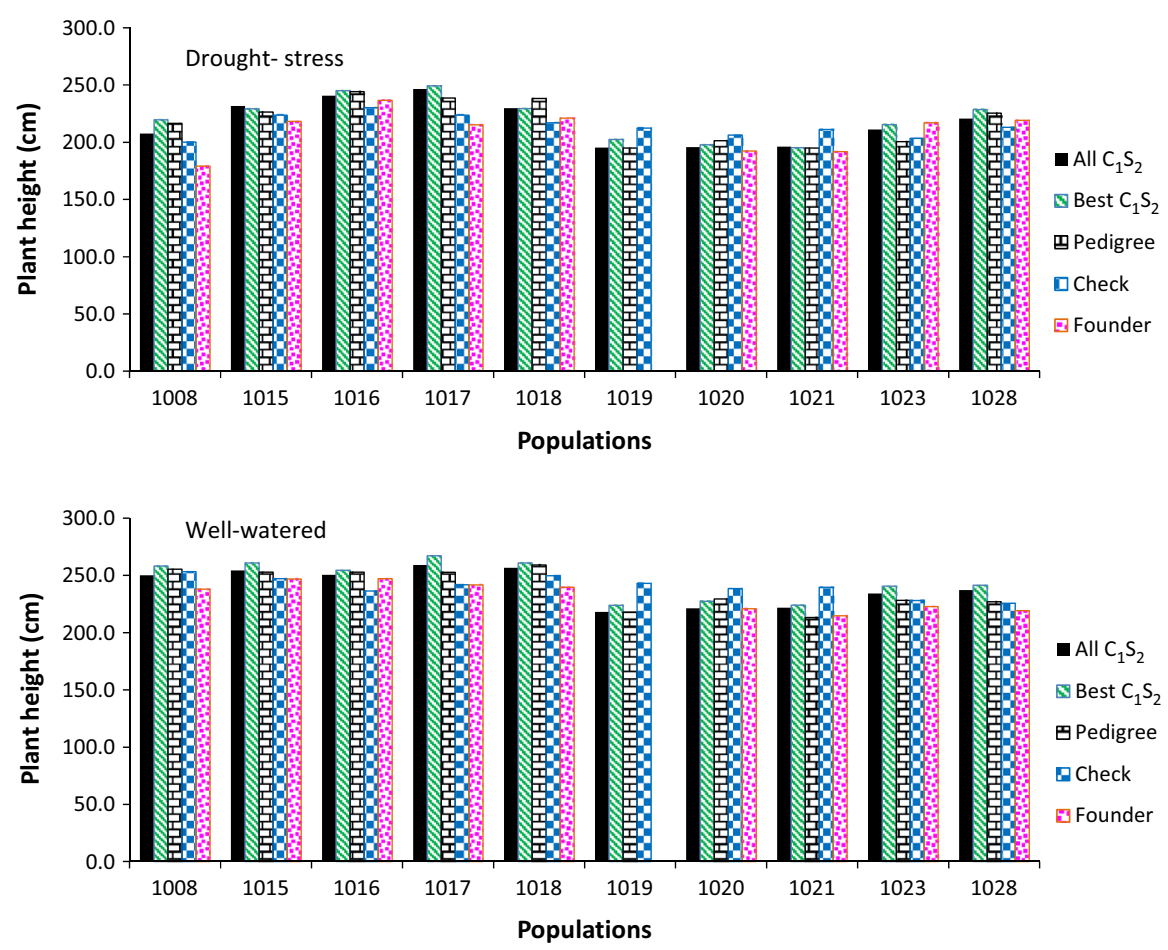
the $103.9 \mathrm{~kg} \mathrm{ha}^{-1}$ year $^{-1}$ grain yield observed for hybrids developed using the pedigree method.

Mean flowering date of the best 10 hybrids of $\mathrm{C}_{1} \mathrm{~S}_{2^{-}}$ derived lines was generally similar to those hybrids formed from pedigree-derived lines, the founder parents and the commercial checks, with a maximum difference of 1-3 days (Fig. 2, Supplementary material S2). Pairwise comparisons of mean plant height of the different groups were significant for most populations (Supplementary material S2). The best 10 hybrids of $\mathrm{C}_{1} \mathrm{~S}_{2}$-derived lines were 6-14.5 and $11-25.3 \mathrm{~cm}$ taller than the hybrids formed from pedigree derived lines and the commercial checks, respectively, in six populations (Fig. 3, Supplementary material S2). Compared with the commercial checks, the best 10 hybrids involving $\mathrm{C}_{1} \mathrm{~S}_{2}$ derived lines were $11.0-19.2 \mathrm{~cm}$ shorter in three populations (1019, 1020, and 1021).

\section{Grain yield stability}

To compare grain yield stability of the best 10 hybrids of $\mathrm{C}_{1} \mathrm{~S}_{2}$-derived lines with that of hybrids formed from pedigree derived lines, commercial checks and founders, we selected two populations (1016 and 1017) that were evaluated in three DS locations, and four populations $(1015,1021,1023$ and 1028) that were evaluated in five WW locations. Figure 4 summarizes biplots of the grain yield of the two populations evaluated under DS conditions. The first two axes from the GGE biplot for populations 1016 and 107 explained 87.6 and $80.1 \%$, respectively, of the genotypic main effect. The two-dimensional biplot showed that almost all of the best 10 hybrids of $\mathrm{C}_{1} \mathrm{~S}_{2^{-}}$ derived lines had positive PC1 scores, suggesting they had above average performance. In population 1016, four hybrids derived from $\mathrm{C}_{1} \mathrm{~S}_{2}$ (entries 10, 34, 25,31 and 47) were high yielding and stable, with high PC1 scores and near-zero PC2 scores.

The superior grain yield of most of the best 10 hybrids of $\mathrm{C}_{1} \mathrm{~S}_{2}$-derived lines over the five hybrids involving pedigree-derived lines is depicted in Figs. 4 and 5. The majority of the top hybrids derived from $\mathrm{C}_{1} \mathrm{~S}_{2}$ were consistently located towards the upper right quadrant of the biplots, indicating that those entries had both a positive interaction with those environments and higher mean grain yield than entries located on the left-hand side of the biplots (opposite to the direction of the sites). The GGE biplot for populations
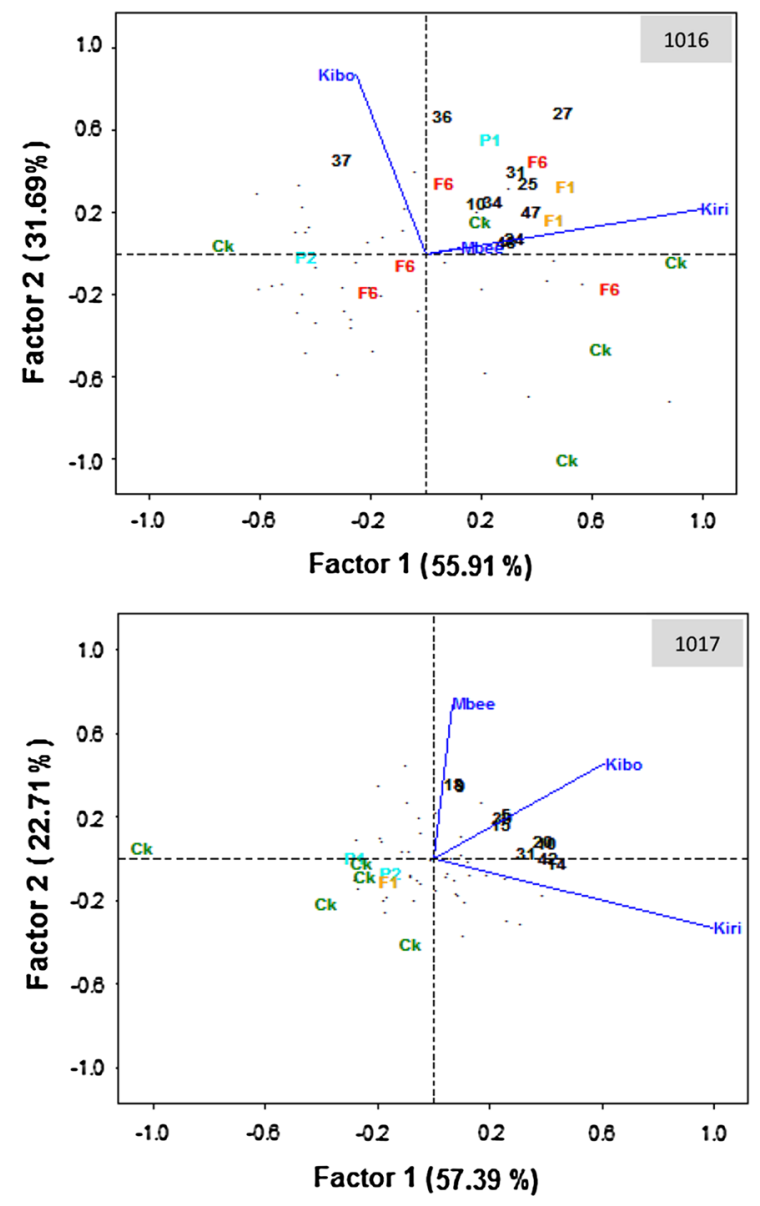

Fig. 4 Biplot of the site regression model (SREG) for two biparental populations evaluated in three managed droughtstressed sites (Kiboko, Kiri and Mbee) in Kenya. Each population is represented by the best 10 hybrids derived from $\mathrm{C}_{1} \mathrm{~S}_{2}$ (black numbers) (other entries from the $\mathrm{C}_{1} \mathrm{~S}_{2}$ are represented by a black dot), commercial checks (abbreviated as $\mathrm{Ck}$ in green color), the 5 hybrids derived from the pedigree method (F6 in red) and founder parents P1 and P2 (light blue). (Color figure online)

1015, 1021, 1023 and 1028 evaluated in five WW environments explained 53.5-73.8\% of the genotypic main effect (Fig. 5). The two-dimensional biplot showed that almost all of the best 10 hybrids of $\mathrm{C}_{1} \mathrm{~S}_{2}$-derived lines had positive PC1 scores, suggesting above average performance, while most pedigree derived hybrids and the commercial checks had negative PC1 scores, indicating below average performance. Embu, Kakamega and Kaguru had longer vectors than the other locations, suggesting that they were the best locations for discriminating hybrids. In population 1023, most hybrids (entries 11, 42, 23, 6 

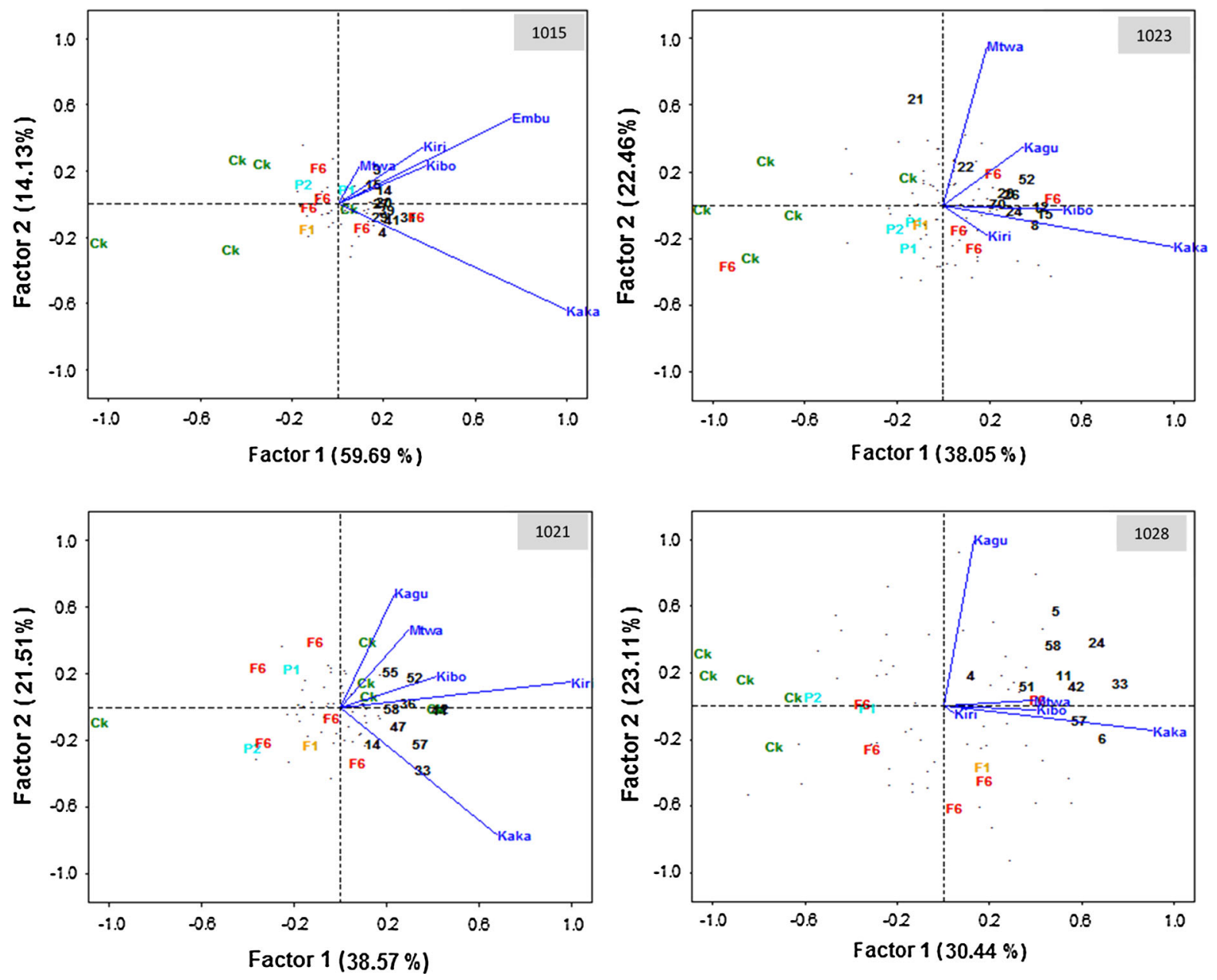

Fig. 5 Biplot of the site regression model (SREG) for four biparental populations evaluated in five well-watered sites in Kenya. Each population is represented by the best 10 hybrids derived from $\mathrm{C}_{1} \mathrm{~S}_{2}$ (black numbers) other $\mathrm{C}_{1} \mathrm{~S}_{2}$ entries are

and 57) had high and stable yields, as they have high positive PC1 scores and near zero PC2 scores. In some populations, the best 10 hybrids of $\mathrm{C}_{1} \mathrm{~S}_{2}$-derived lines that had high grain yield under DS were also found to be among the best 10 under WW conditions (Table 2). For example, entries 27, 36 and 37 from population 1016 were among the best 10 hybrids of $\mathrm{C}_{1} \mathrm{~S}_{2}$-derived lines in both DS and WW locations (Fig. 5; Table 2).

\section{Discussion}

Conventional pedigree breeding has been used successfully to develop improved maize germplasm with abiotic and biotic stress resilience. Since 2007, CIMMYT and

represented by a black dot, commercial checks (abbreviated as $\mathrm{Ck}$ and given in green color), the 5 hybrids derived from the pedigree method (F6 in red) and founder parents P1 and P2 (light blue). (Color figure online)

partners have used conventional breeding methods to develop and release over 200 drought tolerant hybrids and open-pollinated maize varieties in SSA under the framework of the Drought Tolerant Maize for Africa project (DTMA 2015). However, developing improved varieties using conventional breeding methods takes long, since many economically important traits require simultaneous accumulation of favorable alleles from several genomic regions. The use of molecular markers within breeding pipelines is widely, and successfully, employed by large private sector companies (Johnson 2004; Eathington et al. 2007). Use of molecular markers for tropical maize improvement in the developing world is however, constrained by several bottlenecks (Xu et al. 2012; Mba et al. 2012). 
Table 2 Entry code of the best $10 \mathrm{C}_{1} \mathrm{~S}_{2}$ derived hybrids and their grain yield $(\mathrm{GY})\left(\mathrm{t} \mathrm{ha}^{-1}\right)$ in water-stress and well-watered locations for each of the ten biparental populations

\begin{tabular}{|c|c|c|c|c|c|c|c|}
\hline \multicolumn{2}{|c|}{ Drought-stress } & \multicolumn{2}{|c|}{ Well-watered } & \multicolumn{2}{|c|}{ Drought-stress } & \multicolumn{2}{|c|}{ Well-watered } \\
\hline Entry & GY & Entry & GY & Entry & GY & Entry & GY \\
\hline \multicolumn{4}{|c|}{ Population 1008} & \multicolumn{4}{|c|}{ Population 1015} \\
\hline 43 & 4.008 & 14 & 7.997 & 47 & 3.196 & 20 & 7.089 \\
\hline 46 & 3.891 & 48 & 7.909 & 2 & 3.119 & 31 & 7.059 \\
\hline 6 & 3.801 & 41 & 7.713 & 10 & 2.614 & 3 & 7.037 \\
\hline 17 & 3.722 & 42 & 7.669 & 19 & 2.490 & 14 & 6.932 \\
\hline 14 & 3.622 & 5 & 7.608 & 22 & 2.415 & 27 & 6.867 \\
\hline 49 & 3.556 & 35 & 7.576 & 38 & 2.375 & 29 & 6.840 \\
\hline 13 & 3.551 & 18 & 7.550 & 42 & 2.371 & 15 & 6.825 \\
\hline 25 & 3.545 & 1 & 7.550 & 25 & 2.365 & 4 & 6.797 \\
\hline 27 & 3.541 & 7 & 7.541 & 44 & 2.359 & 39 & 6.795 \\
\hline 21 & 3.502 & 25 & 7.468 & 46 & 2.353 & 41 & 6.767 \\
\hline \multicolumn{4}{|c|}{ Population 1016} & \multicolumn{4}{|c|}{ Population 1017} \\
\hline 36 & 3.068 & 37 & 8.672 & 42 & 4.352 & 25 & 8.905 \\
\hline 47 & 3.024 & 31 & 8.473 & 10 & 4.300 & 24 & 8.672 \\
\hline 48 & 3.021 & 30 & 8.239 & 14 & 4.268 & 27 & 8.653 \\
\hline 27 & 2.994 & 27 & 8.167 & 20 & 4.246 & 11 & 8.581 \\
\hline 24 & 2.952 & 36 & 8.129 & 17 & 4.069 & 40 & 8.560 \\
\hline 10 & 2.914 & 35 & 8.057 & 16 & 4.060 & 28 & 8.555 \\
\hline 37 & 2.913 & 26 & 8.008 & 31 & 4.015 & 34 & 8.492 \\
\hline 25 & 2.903 & 44 & 7.963 & 19 & 4.014 & 14 & 8.487 \\
\hline 34 & 2.877 & 34 & 7.937 & 27 & 3.943 & 26 & 8.464 \\
\hline 31 & 2.863 & 32 & 7.923 & 5 & 3.935 & 4 & 8.463 \\
\hline \multicolumn{4}{|c|}{ Population 1018} & \multicolumn{4}{|c|}{ Population 1019} \\
\hline 8 & 2.831 & 8 & 7.038 & 52 & 2.890 & 2 & 7.370 \\
\hline 52 & 2.651 & 60 & 6.939 & 56 & 2.881 & 1 & 7.121 \\
\hline 60 & 2.647 & 44 & 6.858 & 41 & 2.822 & 12 & 7.069 \\
\hline 4 & 2.639 & 42 & 6.616 & 42 & 2.790 & 3 & 7.046 \\
\hline 36 & 2.574 & 10 & 6.603 & 1 & 2.786 & 50 & 6.821 \\
\hline 35 & 2.542 & 38 & 6.586 & 29 & 2.712 & 23 & 6.748 \\
\hline 46 & 2.462 & 53 & 6.565 & 9 & 2.640 & 29 & 6.643 \\
\hline 14 & 2.455 & 7 & 6.543 & 55 & 2.624 & 51 & 6.634 \\
\hline 41 & 2.427 & 22 & 6.542 & 11 & 2.605 & 52 & 6.617 \\
\hline 32 & 2.420 & 30 & 6.488 & 22 & 2.527 & 10 & 6.604 \\
\hline \multicolumn{4}{|c|}{ Population 1020} & \multicolumn{4}{|c|}{ Population 1021} \\
\hline 42 & 3.181 & 5 & 6.374 & 54 & 3.231 & 44 & 7.415 \\
\hline 63 & 2.960 & 25 & 6.368 & 63 & 3.223 & 55 & 7.412 \\
\hline 40 & 2.914 & 12 & 6.257 & 57 & 3.218 & 33 & 7.368 \\
\hline 36 & 2.726 & 29 & 6.180 & 14 & 3.153 & 12 & 7.309 \\
\hline 62 & 2.676 & 62 & 6.169 & 51 & 3.086 & 57 & 7.189 \\
\hline 45 & 2.642 & 28 & 6.164 & 27 & 3.066 & 36 & 7.178 \\
\hline 25 & 2.620 & 40 & 6.149 & 7 & 3.053 & 14 & 7.149 \\
\hline 53 & 2.578 & 57 & 6.132 & 39 & 3.019 & 52 & 7.137 \\
\hline
\end{tabular}


Table 2 continued

\begin{tabular}{|c|c|c|c|c|c|c|c|}
\hline \multicolumn{2}{|c|}{ Drought-stress } & \multicolumn{2}{|c|}{ Well-watered } & \multicolumn{2}{|c|}{ Drought-stress } & \multicolumn{2}{|c|}{ Well-watered } \\
\hline Entry & GY & Entry & GY & Entry & GY & Entry & GY \\
\hline 50 & 2.511 & 63 & 6.128 & 40 & 2.997 & 58 & 7.121 \\
\hline 19 & 2.507 & 4 & 6.105 & 6 & 2.993 & 47 & 7.115 \\
\hline \multicolumn{4}{|c|}{ Population 1023} & \multicolumn{4}{|c|}{ Population 1028} \\
\hline 51 & 3.944 & 12 & 7.583 & 19 & 3.561 & 33 & 7.602 \\
\hline 72 & 2.919 & 20 & 7.574 & 16 & 3.489 & 24 & 7.511 \\
\hline 20 & 2.849 & 52 & 7.388 & 59 & 3.363 & 57 & 7.363 \\
\hline 41 & 2.722 & 70 & 7.300 & 60 & 3.362 & 51 & 7.326 \\
\hline 26 & 2.713 & 60 & 7.288 & 7 & 3.183 & 5 & 7.323 \\
\hline 35 & 2.682 & 26 & 7.218 & 18 & 3.180 & 4 & 7.265 \\
\hline 17 & 2.678 & 22 & 7.207 & 54 & 3.103 & 42 & 7.242 \\
\hline 23 & 2.610 & 11 & 7.154 & 12 & 3.085 & 6 & 7.208 \\
\hline 14 & 2.609 & 46 & 7.152 & 11 & 3.062 & 11 & 7.199 \\
\hline 25 & 2.605 & 24 & 7.142 & 61 & 3.059 & 58 & 7.176 \\
\hline
\end{tabular}

Bolditalic indicates the entry number of hybrids that performed well both under WW and DS conditions

To facilitate the development and use of improved tropical maize germplasm, CIMMYT in collaboration with public and private partners conducted the largest public MARS and GS projects as part of both the Water Efficient Maize for Africa (WEMA) and DTMA projects. Based on the genetic gain data collected by these projects across multiple populations, each represented by a composite bulk of lines, we recently demonstrated the superiority of MARS for increasing grain yield under DS and WW conditions across diverse tropical maize populations without significantly affecting plant height and maturity of most populations (Beyene et al. 2015a; Semagn et al. 2015). When genetic gains for individual populations were considered, results indicated that different populations showed deferent responses to MARS, with the majority of the populations producing higher grain yields than those developed using conventional breeding methods. A smaller number of populations showed either similar or no gain in grain yield under both WW and DS conditions as compared with those developed through pedigree selection. A possible factor contributing to the lack of gain in grain yield from those populations may be the representation of every population by a composite bulk prior to testcross formation, which was implemented primarily to minimize the number of entries to be evaluated.

In the present study, hybrids developed by crossing 47-74 $C_{1} S_{2}$ lines from each of the 10 MARS populations with a single cross tester were evaluated. Combined across all DS locations and populations, the best $10 \mathrm{C}_{1} \mathrm{~S}_{2}$-derived hybrids produced 562,750 and $916 \mathrm{~kg} \mathrm{ha}^{-1}$ higher grain yield than pedigree-derived hybrids, commercial checks and founder parents, respectively. In WW locations, the best $10 \mathrm{C}_{1} \mathrm{~S}_{2^{-}}$ derived hybrids produced 583, 1305 and $1557 \mathrm{~kg} \mathrm{ha}^{-1}$ more grain yield than pedigree-derived hybrids, commercial checks and founder parents, respectively.

As previously described by Beyene et al. (2015b) 3.5 years were required to develop $S_{5}$ lines through pedigree selection and 4 years to develop $C_{1} S_{2}$ lines through MARS. Considering the number of years spent in developing the lines used in the study and taking the grain yield of the founder parents as the baseline data, the top 10 hybrids of $\mathrm{C}_{1} \mathrm{~S}_{2}$-derived lines on average yielded 229 and $389.3 \mathrm{~kg} \mathrm{ha}^{-1}$ year $^{-1}$ in DS and WW conditions, respectively, which is higher than the yield of the hybrids formed from pedigreederived lines $\left(27.2 \mathrm{~kg} \mathrm{ha}^{-1}\right.$ year $^{-1}$ under DS and $103.9 \mathrm{~kg} \mathrm{ha}^{-1}$ year $^{-1}$ under WW). The overall gains from the best 10 hybrids of $\mathrm{C}_{1} \mathrm{~S}_{2}$-derived lines in the present study were higher than previous results reported by Beyene et al. (2015b) using composite bulk sampling. Although composite bulking of $\mathrm{C}_{1} \mathrm{~S}_{2}$ lines prior to hybrid formation and their evaluation under multiple environments provided an overall idea of the genetic gain obtained through MARS over pedigree selection, results of the present study clearly 
demonstrate the value of evaluating every $\mathrm{C}_{1} \mathrm{~S}_{2^{-}}$ derived hybrid to identify the best lines for further inbreeding and hybrid development. As shown in Supplementary material S2, the top 10 hybrids of $\mathrm{C}_{1} \mathrm{~S}_{2}$-derived lines from each of the 10 biparental populations produced higher mean grain yields than hybrids developed using pedigree derived lines This result is similar to the findings of Eathington et al. (2007), who compared MARS and conventional selection in 248 North American and European maize breeding populations, and reported higher performance and yield index gains for MARS that was more than doubled compared to phenotypic selection. They also found that the MARS-derived lines were higher performing compared to conventionally selected lines.

A recent review of genetic gain studies from conventional pedigree selection conducted both in temperate and tropical maize germplasm reported highly variable results (Edmeades 2013). In SSA, preliminary estimates of yield gains from conventional selection revealed 39-80 $\mathrm{kg} \mathrm{ha}^{-1}$ year $^{-1}$ under optimal conditions, but only $18 \mathrm{~kg} \mathrm{ha}^{-1}$ year $^{-1}$ under drought stress (Edmeades 2013). A recent study using 67 hybrids developed at CIMMYT and released between 2000 and 2011 showed genetic gains of 32 and $109 \mathrm{~kg} \mathrm{ha}^{-1}$ year $^{-1}$ for grain yield under managed drought and wellwatered conditions, respectively (Masuka et al. 2015, submitted). Therefore, the overall average gain obtained under DS (229 kg ha ${ }^{-1}$ year $\left.^{-1}\right)$ and WW $(389.3 \mathrm{~kg}$ $\mathrm{ha}^{-1}$ year $^{-1}$ ) in the current study was three to seven times higher than that reported from conventional phenotypic selection in SSA. Genetic gains obtained through pedigree breeding in the current study (27.2 and $103.9 \mathrm{~kg} \mathrm{ha}^{-1}$ year $^{-1}$ under DS and WW conditions, respectively) were similar to estimates reported in the literature in SSA (Edmeades 2013).

Edmeades et al. (2004) reported that the phenotypic correlation between elite hybrid yields under stress versus under well-watered conditions declined as stress intensified, reaching $0.35\left(r^{2}=0.12\right)$ when yield reductions reached $50 \%$. They suggested that stress adaptive mechanisms were not exposed until yields had been reduced by $30-50 \%$ under stress. In the current study, the average grain yield were $6.60 \mathrm{t} \mathrm{ha}^{-1}$ under WW condition and $2.61 \mathrm{t} \mathrm{ha}^{-1}$ under DS condition, which represented a $61 \%$ yield reduction, approaching the $70 \%$ yield reduction typically targeted by CIMMYT in managed drought stress experiments in SSA (Bänziger et al. 2000). Accordingly, the best $10 \mathrm{C}_{1} \mathrm{C}_{2}$ lines identified in these studies from each population may have adaptive traits for drought tolerance, which could be utilized as sources of drought tolerance in maize breeding.

Relative differences in genetic gains observed between MARS and pedigree selection were much higher under DS conditions than under WW conditions), suggesting that MARS could accelerate the pace of improvement, for complex traits such as drought tolerance. These results agree with previous reports (Eathington et al. 2007; Xu and Crouch 2008; Beyene et al. 2015b), indicating that MARS can be more efficient and effective than phenotypic selection, and could improve genetic gains for complex traits like drought tolerance in tropical maize breeding programs.

Since drought incidence and severity vary considerably among years and within fields, it is important to develop hybrids that are able to withstand drought stress throughout the growing season, but also have no yield penalty under optimum conditions. Hybrids performing well under both DS and WW conditions were identified in this study (Table 2). For example, entries 14 and 25 in population 1008 and entries 27, 36, and 37 in population 1016 are among the top performing hybrids under both DS and WW conditions. Therefore, the parents of these hybrids need to be fixed through generation of inbreeding to develop hybrids that will perform better both under drought stress and well water conditions.

Acknowledgments The results reported in this paper were generated as part of the Water Efficient Maize for Africa project, funded by the Bill and Melinda Gate and the Howard G Buffet Foundations. The authors would like to thank, Joel Mbithi, Patrick Gichobi, David Karuri and Gabriel Ambani for data collection at the various experimental sites.

Open Access This article is distributed under the terms of the Creative Commons Attribution 4.0 International License (http:// creativecommons.org/licenses/by/4.0/), which permits unrestricted use, distribution, and reproduction in any medium, provided you give appropriate credit to the original author(s) and the source, provide a link to the Creative Commons license, and indicate if changes were made.

\section{References}

Almeida GD, Makumbi D, Magorokosho C, Nair S, Borem A, Ribaut J-M, Bänziger M, Prasanna BM, Crossa J, Babu R (2013) QTL mapping in three tropical maize populations reveals a set of constitutive and adaptive genomic regions 
for drought tolerance. Theor Appl Genet 126:583-600. doi:10.1007/s00122-012-2003-7

Bänziger M, Edmeades GO, Beck D, Bellon M (2000) Breeding for drought and nitrogen stress tolerance in maize: from theory to practice. CIMMYT, Mexico

Bernardo R (2008) Molecular markers and selection for complex traits in plants: learning from the last 20 years. Crop Sci 48:1649-1664

Beyene Y, Mugo S, Pillay K, Tefera T, Njoka SA, Karaya H, Gakunga J (2011) Testcross performance of doubled haploid maize lines derived from tropical adapted backcross populations. Maydica 56:351-358

Beyene Y, Tarekegne A, Gakunga J, Mugo S, Tefera T, Karaya H, Semagn K, Gethi J, Chavangi A, Asea G, Kiula B, Trevisan W (2013) Genetic distance among doubled haploid maize lines and their testcross performance under drought stress and non-stress conditions. Euphytica 192:379-392

Beyene Y, Semagn K, Mugo S, Tarekegne A, Babu R, Meisel B, Sehabiague P, Makumbi D, Magorokosho C, Oikeh S, Gakunga J, Vargas M, Olsen M, Prasanna BM, Banziger M, Crossa J (2015a) Genetic gains in grain yield through genomic selection in eight bi-parental maize populations under drought stress. Crop Sci 55:154-163. doi:10.2135/ cropsci2014.07.0460

Beyene Y, Semagn K, Crossa J, Mugo S, Atlin G, Tarekegne A, Sehabiague P, Vivel BS, Oikeh S, Alvarado G, Machida L, Olsen M, Prasanna BM, Banziger M (2015b) Improving maize grain yield under drought stress and non-stress conditions in sub-Saharan Africa using marker-assisted recurrent selection. Crop Sci. doi:10.2135/cropsci2015.02. 0135

Crossa J, Cornelius P (1997) Sites regression and shifted multiplicative model clustering of cultivar trial sites under heterogeneity of error variances. Crop Sci 37:406-415

DTMA (2015) A new generation of maize for Africa. http://dtma. cimmyt.org/index.php/publications/doc_view/196-a-newgeneration-of-maize-for-africa. Accessed 7 Nov 2015

Eathington SR, Crosbie TM, Edwards MD et al (2007) Molecular markers in a commercial breeding program. Crop Sci 47:S154-S163. doi:10.2135/cropsci2007.04.0015IPBS

Edmeades GO (2013) Progress in achieving and delivering drought tolerance in maize - an update. International service for the acquisition of agri-biotech applications (ISAAA), Ithaca, NY

Edmeades GO, Banziger M, Schussler JR, Campos H (2004) Improving abiotic stress tolerance in maize: a random or planned process? In: Proceedings of the Arnel R. Hallauer International symposium on plant breeding, Mexico City, 17-22 August 2003, Iowa State University Press

Heisey PW, Edmeades GO (1999) CIMMYT 1997/98 world maize facts and trends; maize production in droughtstressed environments: technical options and research resource allocation. CIMMYT, Mexico

Johnson R (2004) Marker-assisted selection. Plant Breed Rev 24:293-309
Masuka B, Atlin GN, Olsen M, Labuschange M, Crossa J, von Biljon A, MacRobert J, Magorokosho C, Prasanna BM, Makumbi D, Tarekegne A, Das B, Zaman-Allah M, Banziger M, Cairns JE (2015) Gains in maize genetic improvement in Eastern and Southern Africa i) hybrid breeding pipeline. Crop Sci (submitted)

Mba C, Guimaraes EP, Ghosh K (2012) Re-orienting crop improvement for the changing climatic conditions of the 21st century. Agric Food Secur 1:7

Meuwissen THE, Hayes BJ, Goddard ME (2001) Prediction of total genetic value using genome-wide dense marker maps. Genetics 157:1819-1829

Prasanna BM, Cairns J, Xu Y (2013) Genomic tools and strategies for breeding climate resilient cereals. In: Kole C (ed) Genomics and breeding for climate resilient crops. Concepts and strategies, vol 1. Springer, Heidelberg, pp 213-239

Ribaut JM, Jiang C, Gonzalez-de-Leon D, Edmeades GO, Hoisington DA (1997) Identification of quantitative trait loci under drought conditions in tropical maize. 2. Yield components and marker-assisted selection strategies. Theor Appl Genet 94:887-896. doi:10.1007/s001220050 492

SAS Institute (2009) The SAS system for windows. SAS Institute Inc., Cary

Semagn K, Beyene Y, Warburton ML, Tarekegne A, Mugo S, Meisel B, Sehabiague P, Prasanna B (2013) Meta-analyses of QTL for grain yield and anthesis silking interval in 18 maize populations evaluated under water-stressed and well-watered environments. BMC Genom 14:313. doi:10. 1186/1471-2164-14-313

Semagn K, Beyene Y, Babu R, Nair S, Gowda M, Das B, Tarekegne A, Mugo S, Mahuku G, Worku M, Warburton ML, Olsen M, Prasanna BM (2015) Quantitative trait loci mapping and molecular breeding for developing stress resilient maize for sub-Saharan Africa. Crop Sci 55:1-55. doi:10.2135/cropsci2014.09.0646

Shiferaw B, Prasanna BM, Hellin J, Banziger M (2011) Crops that feed the world 6. Past successes and future challenges to the role played by maize in global food security. Food Secur 3:307. doi:10.1007/s12571-011-0140-5

Tuberosa R, Salvi S, Sanguineti MC, Landi P, Maccaferri M, Conti S (2002) Mapping QTLs regulating morpho-physiological traits and yield: case studies, shortcomings and perspectives in drought-stressed maize. Ann Bot 89:941-963. doi:10.1093/aob/mcFounder34

Veldboom LR, Lee M (1996) Genetic mapping of quantitative trait loci in maize in stress and non-stress environments: I. Grain yield and yield components. Crop Sci 36:1310. doi:10.2135/cropsci1996.0011183X003600050040x

Xu Y, Crouch JH (2008) Marker-assisted selection in plant breeding: from publications to practice. Crop Sci 48:391-407

Xu Y, Lu Y, Xie C, Gao S, Wan J, Prasanna BM (2012) Wholegenome strategies for marker-assisted plant breeding. Mol Breed 29:833-854 